\title{
Prognostic utility of fluorescence in situ hybridization for determining HER2 gene amplification in breast cancer
}

\author{
MAKOTO KAMMORI ${ }^{1-4}$, RIE KURABAYASHI ${ }^{2,3}$, MITSUHIKO KASHIO ${ }^{3,4}$, \\ AKIKO SAKAMOTO ${ }^{4}$, MASATAKA YOSHIMOTO ${ }^{5}$, SADAO AMANO ${ }^{4}$, \\ MICHIO KAMINISHI $^{2}$, TETSU YAMADA ${ }^{1}$ and KAIYO TAKUBO ${ }^{3}$
}

\begin{abstract}
${ }^{1}$ Department of Surgery, Kanaji Thyroid Hospital; ${ }^{2}$ Division of Breast and Endocrine Surgery, Department of Surgery, Graduate School of Medicine, The University of Tokyo; ${ }^{3}$ Human Tissue Research Group, Tokyo Metropolitan Institute of Gerontology; ${ }^{4}$ Division of Breast and Endocrine Surgery, Department of Surgery, Nihon University School of Medicine; ${ }^{5}$ Breast Center, Mita Hospital, International University of Health and Welfare, Tokyo, Japan
\end{abstract}

Received October 9, 2007; Accepted December 3, 2007

\begin{abstract}
An accurate investigation of the HER2 protooncogene is extremely important for the therapy and prognostication of breast cancer. Currently, immunohistochemistry (IHC) and fluorescence in situ hybridization (FISH) are standard methods for this purpose. The aim of this study was to detect the expression and amplification of HER2 in paraffin-embedded samples of breast cancer tissue and to investigate the relationship between HER 2 amplification and various clinicopathological parameters in advanced breast cancers. We used FISH to examine the HER2 gene amplification and IHC to examine the expression of HER2 protein, estrogen receptor (ER) and progesterone receptor (PR) in 62 advanced breast cancers. HER2 gene amplification was detected by FISH in 12 breast cancers (19\%) and HER 2 protein expression with a score of $3^{+}$was detected by IHC in $11(17 \%)$. There was a significant correlation between the HER2 gene amplification and HER2 protein overexpression in breast cancers $(\mathrm{P}<0.0001)$. However, some mismatching was evident: 3 cases, negative for the HER2 gene, showed a HER2 protein expression score of $3^{+}$and 2 cases, positive for HER 2 gene amplification, had HER2 protein expression scores of 0 and $1^{+}$ (negative), respectively. ER and PR were expressed in 41 (66\%) and $46(74 \%)$ cancers, respectively. No correlation was observed between the HER2 gene amplification and any of the clinicopathological parameters examined, including age, histopathological type, TNM stage, tumor size, lymph node status, relapse and expression of PR. We observed three patterns among the 6 deceased cases: i) triple negativity for
\end{abstract}

Correspondence to: Dr Makoto Kammori, Department of Surgery, Kanaji Thyroid Hospital, 1-5-6 Nakazato Kita-ku, Tokyo 114-0015, Japan

E-mail: kanmori-dis@umin.ac.jp

Key words: HER2, immunohistochemistry, fluorescence in situ hybridization, estrogen receptor, progesterone receptor, breast cancer
HER2, ER and PR, ii) positivity for HER2 gene amplification with a mismatching HER2 protein expression, and iii) positivity for the HER2 gene amplification with a matching HER2 protein expression score of $2^{+}$or $3^{+}$. The triple negative cases and HER2 gene amplification positive cases with a mismatching HER2 protein expression had a poor outcome. These results suggest that in breast cancer, the detection of HER2 gene amplification by FISH is desirable compared with the HER2 protein expression determined by IHC. Moreover, triple negativity for HER2, ER and PR is a potentially very important prognostic marker.

\section{Introduction}

HER2 is a proto-oncogene located at 17q12-21.32. The encoded product is a transmembrane $185-\mathrm{kDa}$ protein with tyrosine kinase activity that belongs to the type I epidermal growth factor receptor family (1) and is known to be involved in signal transduction during cell growth $(2,3)$. The amplification of the gene and concomitant overexpression of the HER2 protein has been identified in $10-34 \%$ of breast carcinomas and is considered to be not only an important biological marker of poor prognosis but also a useful indicator of response to chemotherapy or endocrine therapy $(2,4)$. The development of the new anticancer drug trastuzumab, which is a recombinant humanized monoclonal antibody against the extracellular portion of the HER2 protein, and the encouraging results obtained from the treatment of patients whose breast carcinomas demonstrated HER2 amplification and/or overexpression have led to a renewed interest in HER2. Therefore, laboratory assessment of HER2 gene status has become a basic procedure for the appropriate management of breast cancer patients (5).

Currently, the HER2 status is examined using fluorescence in situ hybridization (FISH) and immunohistochemistry (IHC) which are recommended by national and international guidelines (6). IHC has been used mainly in pathology laboratories in a routine setting for the detection of HER2 overexpression in archival material from breast carcinomas. However, the results of IHC are affected by technical factors 
related to fixation and methodological differences such as the type of antibody and the scoring system used (4). Since the ability of IHC to detect HER2 protein depends on the presence of oncogene amplification, FISH analysis, which defines the number of gene copies in the cancer cell nucleus, is now sometimes used as an alternative or adjunctive technique for the evaluation of HER2 status. The FISH technique requires expensive fluorescence microscopy, with all the concomitant disadvantages of evaluating and retaining the hybridization signal (6-8).

The purpose of this study was to evaluate the HER2 gene status in relation to chromosome 17 polysomy using the FISH technique as compared with the results of IHC and to evaluate the expression of ER and PR in 62 advanced breast cancers.

\section{Materials and methods}

Tissue specimens. We examined a total of 120 cases of breast cancer, including 62 cases of invasive ductal carcinoma exceeding stage II according to the 1997 WHO classification (7th edition), in patients aged 24-85 who underwent surgery at the University of Tokyo Hospital between July 2001 and June 2002. The surgical tissue samples were frozen rapidly in liquid nitrogen and stored at $-80^{\circ} \mathrm{C}$ until fixation. They were then fixed in $10 \%$ buffered formalin solution and embedded in paraffin. All samples were collected after obtaining informed consent from the patients and the study protocol was approved by the Medical Department of the University of Tokyo ethics committee. The pathological diagnoses were made by specialists in surgical pathology at our institution by examining the hematoxylin-eosin stained slides. All breast tumors were reviewed pathologically on the basis of the BRE score. pT and pN staging was performed according to the 1997 WHO classification (7th edition).

Fluorescence in situ hybridization (FISH). FISH was performed using the PathVysion assay kit (Vysis, Inc., Downers Grove, IL), which involves direct labeling with two DNA probes: a locus-specific probe for the HER2 gene labeled with SpectrumOrange (LSI Her-2/neu) and an $\alpha$ satellite probe targeting the centromere region of chromosome 17 labeled with SpectrumGreen (CEP 17). The assay was performed according to the manufacturer's instructions. In brief, after deparaffinization, specimens were incubated in pretreatment solution $\left(80^{\circ} \mathrm{C}\right.$ for $\left.10 \mathrm{~min}\right)$ and then digested with protease $\left(37^{\circ} \mathrm{C}\right.$ for $15 \mathrm{~min}$ ). The LSI Her2/CEP 17 probe was applied, the slide was sealed with a coverslip and the specimen was hybridized overnight at $37^{\circ} \mathrm{C}$. The slides were then washed, counterstained with DAPI and viewed by fluorescence microscopy. In each breast cancer specimen an average of 60 nuclei was enumerated in the invasive part of the tumor. The HER2 gene copy number, chromosome 17 copy number and the average HER2 gene to chromosome 17 signal ratio were evaluated as FISH genetic variables. Samples with a ratio value of $>2.0$ were considered to be amplified.

Immunohistochemistry (IHC). The expression of the HER2 protein was determined in 5- $\mu \mathrm{m}$ paraffin sections by two-step immunohistochemical staining using a commercial kit (HERcep Test, Dako, Glostrup, Denmark) according to the manufacturer's instructions. After incubation with the primary rabbit antibody against the human HER2 protein, a secondary goat anti-rabbit immunoglobulin conjugated with horseradish peroxidase was applied for visualization. Slides immunostained for ER and PR were scored as previously described $(9,10)$. Each entire slide was evaluated by light microscopy. First, a proportional score was assigned, representing the estimated proportion of positively-stained tumor cells ( 0 , none; 1 , $<1 / 100 ; 2,1 / 100$ to $1 / 10 ; 3,1 / 10$ to $1 / 3 ; 4,1 / 3$ to $2 / 3$ and 5 , $>2 / 3$ ). Then an intensity score was assigned, representing the average intensity of positive staining ( 0 , none; 1 , weak; 2 , intermediate and 3 , strong). The proportion and intensity scores were then added to obtain a total score, which ranged from 0 to 8 . Slides were scored by pathologists who were blinded to ligand-binding results or patient outcome.

Statistical analysis. Differences in P-values were analyzed with the $\chi^{2}$ test for independence. Correlations of the FISH and IHC results with clinicopathological factors were analyzed by the $\chi^{2}$ test, or by Fisher's exact test when the assumptions of the $\chi^{2}$ test were not met. Differences at P-value of $<0.05$ were considered significant.

\section{Results}

Fig. 1 shows a representative sample of a tumor with an amplified HER2 gene (Fig. 1A, ratio $=9.92$, positive) and a tumor with a duplicated HER2 gene (Fig. 1B, ratio $=1.75$, negative). Fig. 2 shows a representative sample of a cancer cell and a cell membrane with an overexpression of the HER2 protein (Fig. 2A, score 0; Fig. 2B, score 1+; Fig. 2C, score $2^{+}$ and Fig. 2D, score $3^{+}$). FISH and IHC were performed to detect HER2 amplification and overexpression simultaneously in 62 samples of invasive ductal carcinoma. Of the 62 samples with an invasive ductal carcinoma component, HER2 gene amplification was detected in 12 cases (19\%) by FISH and protein overexpression (score $3^{+}$) was detected in 11 cases $(17 \%)$ by IHC. There was a significant correlation between the detection of HER2 gene amplification and HER2 protein overexpression in breast cancers $(\mathrm{P}<0.0001)$ (Table I). Only 2 (20\%) of the cases showing a HER2 protein score of $2^{+}$by IHC demonstrated HER2 gene amplification by FISH. The results of the two methods agreed in 57 cases (92\%), but differed from each other in 5 cases. Moreover, the HER2 gene amplification in the absence of protein overexpression was detected in 3 cases, while the HER2 protein overexpression in the absence and gene amplification was detected in 2 cases.

Nuclear signals for the ER (Fig. 3A) and PR (Fig. 3B), as assessed by IHC, were observed in $41(66 \%)$ and $46(74 \%)$, respectively, of the 62 breast cancers with positivity scores ranging from 2 to 8 (Table I). No correlation was observed between the HER2 gene amplification and any of the clinicopathological parameters, including age, histopathological type, TNM stage, tumor size, lymph node status and the expression of PR. However, there was a significant correlation between HER2 gene amplification and ER expression $(\mathrm{P}=0.0148)$ (Table I).

We also investigated the relationship of HER2 gene amplification and protein overexpression with the clinicopathological parameters in 6 deceased cases (Table II). Two 

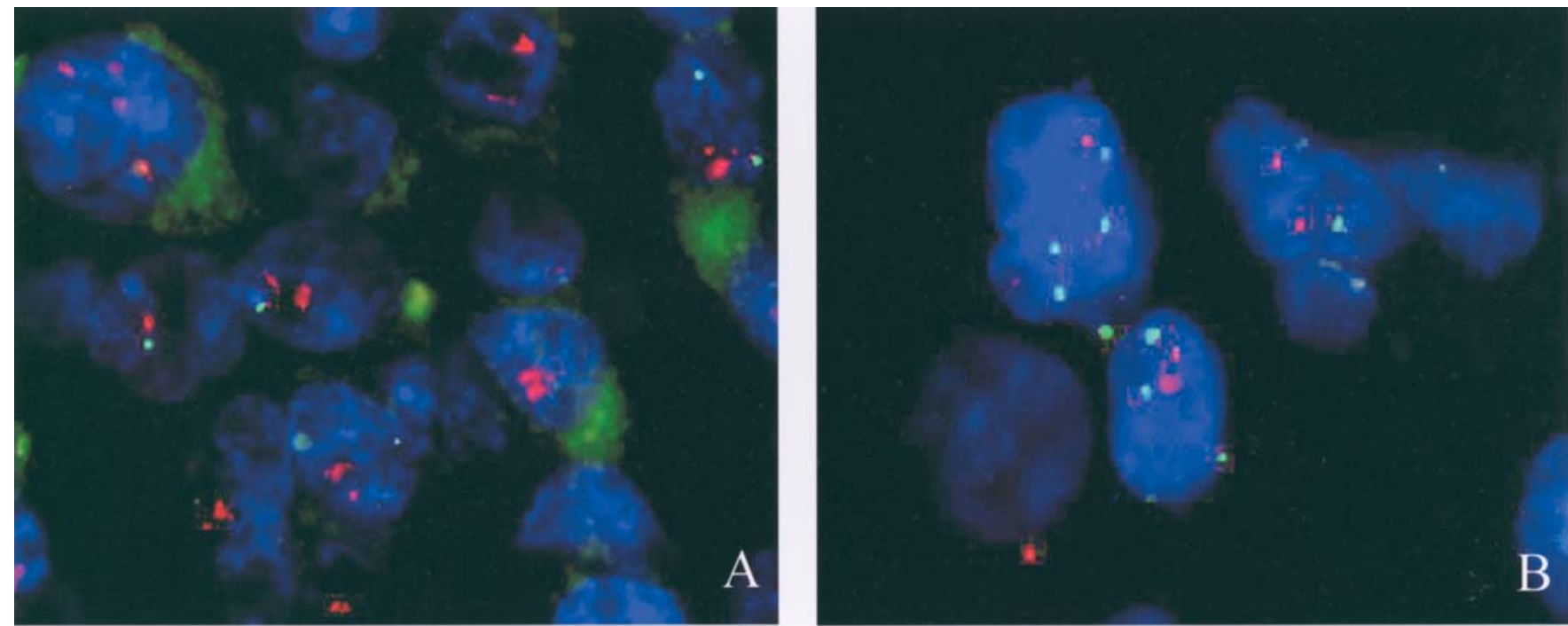

Figure 1. HER2 FISH images: CEP 17 (green) and HER 2 gene (red), HER2 amplification ratio $=$ HER2 signal number/chromosome 17 signal number $=<2.0$ is positive $(+)(\mathrm{A}$ : ratio $=9.92$, positive and $\mathrm{B}$ : ratio $=1.75$, negative $)$
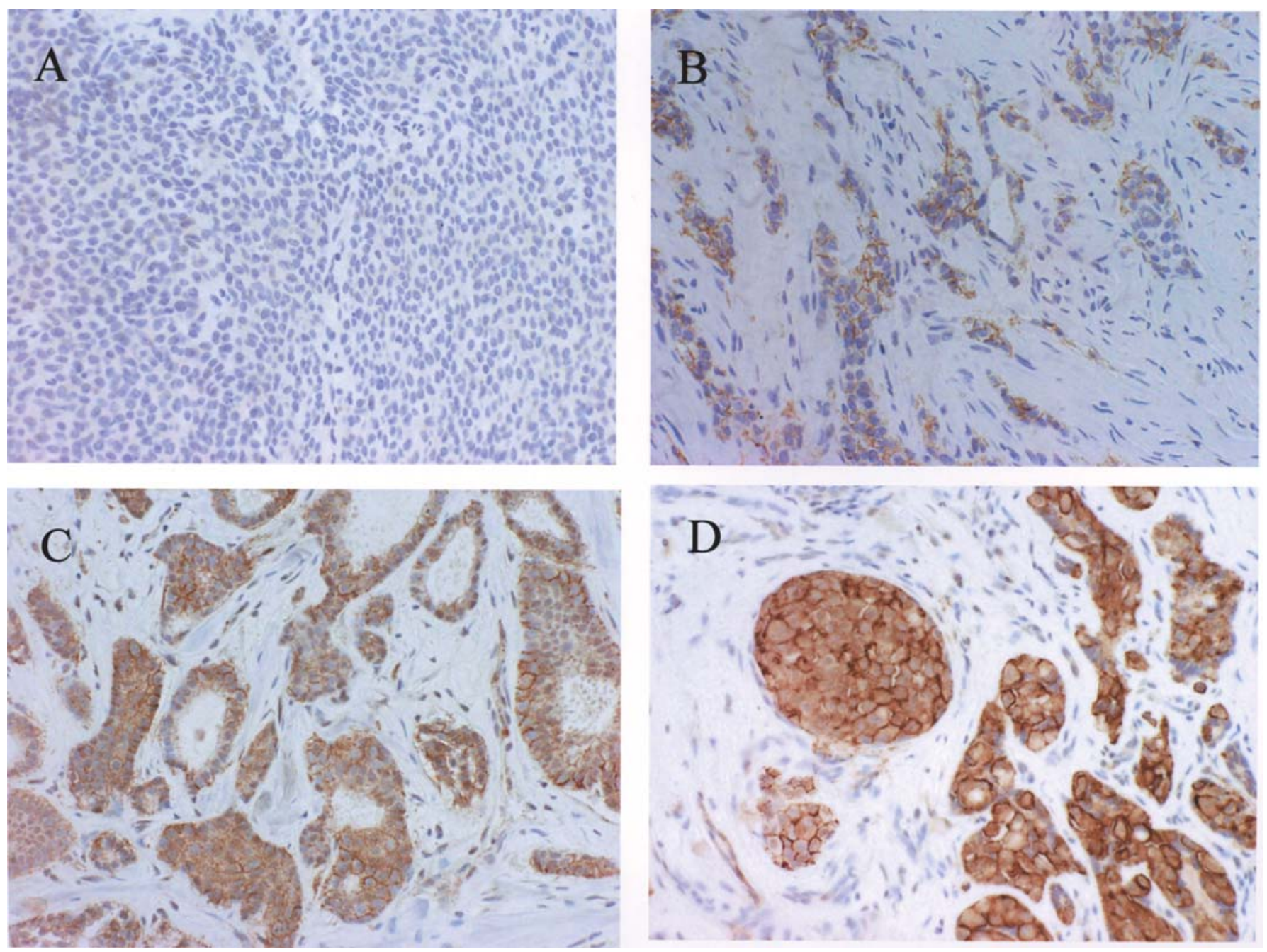

Figure 2. HER2 IHC images: HER2 protein expression scored as $0(\mathrm{~A})$ and $1^{+}(\mathrm{B})$ (negative) or $2^{+}(\mathrm{C})$ and $3^{+}(\mathrm{D})$ (positive) is indicated. 
Table I. Characteristics of the breast cancer patients in this study.

\begin{tabular}{|c|c|c|c|c|}
\hline & \multirow{2}{*}{$\begin{array}{c}\text { Total } \\
\text { number }\end{array}$} & \multicolumn{2}{|c|}{$\begin{array}{c}\text { No. of patients }(\%) \\
\text { HER2 FISH }\end{array}$} & \multirow[b]{2}{*}{$\mathrm{P}^{\mathrm{a}}$} \\
\hline & & Negative & Positive & \\
\hline Patients & 62 & $50(81)$ & $12(19)$ & \\
\hline \multicolumn{5}{|l|}{ Age range ( $24-88$ years) } \\
\hline$\leq 50$ & 23 & $21(91)$ & $2(9)$ & 0.182 \\
\hline$>50$ & 39 & $29(74)$ & $10(16)$ & \\
\hline \multicolumn{5}{|l|}{ Histological tumor type } \\
\hline Invasive ductal carcinoma & 62 & $50(81)$ & $12(19)$ & 0.7905 \\
\hline Scirrhous & 33 & $26(79)$ & $7(21)$ & \\
\hline Papillotubular & 20 & $16(80)$ & $4(20)$ & \\
\hline Solid tubular & 9 & $8(89)$ & $1(11)$ & \\
\hline \multicolumn{5}{|l|}{ Estrogen receptor status } \\
\hline Positive $(\leq 2)$ & 41 & $37(90)$ & $4(10)$ & 0.0148 (Fisher) \\
\hline Negative $(>2)$ & 21 & $13(62)$ & $8(38)$ & \\
\hline \multicolumn{5}{|l|}{ Progesterone receptor status } \\
\hline Positive $(\leq 2)$ & 46 & $38(83)$ & $8(17)$ & 0.4879 (Fisher) \\
\hline Negative $(>2)$ & 16 & $12(75)$ & $4(25)$ & \\
\hline \multicolumn{5}{|l|}{ TNM stage } \\
\hline II & 44 & $35(80)$ & $9(20)$ & 0.6845 \\
\hline III & 15 & $13(87)$ & $2(13)$ & \\
\hline IV & 3 & $2(67)$ & $1(33)$ & \\
\hline \multicolumn{5}{|l|}{ Tumor size } \\
\hline $\mathrm{Tl}(<2.0 \mathrm{~cm})$ & 7 & $6(86)$ & $1(14)$ & 0.8343 \\
\hline $\mathrm{T} 2(2.0-5.0 \mathrm{~cm})$ & 42 & $33(79)$ & $9(21)$ & \\
\hline $\mathrm{T} 3(>5.0 \mathrm{~cm}), \mathrm{T}^{\mathrm{b}}$ & 13 & $11(85)$ & $2(15)$ & \\
\hline \multicolumn{5}{|l|}{ Lymph node status } \\
\hline $\mathrm{pNO}$ & 20 & $16(80)$ & $4(20)$ & 0.9371 \\
\hline $\mathrm{pNl}$ & 35 & $28(80)$ & $7(20)$ & \\
\hline $\mathrm{pN} 2+\mathrm{pNM}$ & 7 & $6(86)$ & $1(14)$ & \\
\hline \multicolumn{5}{|l|}{ HER2 protein (IHC) } \\
\hline Score $0,1^{+}$ & 41 & $39(95)$ & $2(5)$ & $<0.0001$ \\
\hline Score $2^{+}$ & 10 & $8(80)$ & $2(20)$ & \\
\hline Score $3^{+}$ & 11 & $3(27)$ & $8(77)$ & \\
\hline
\end{tabular}

${ }^{\mathrm{a}} \chi^{2}$ test; NS, not significant. ${ }^{\mathrm{b}} \mathrm{T} 4$, direct invasive to chest wall and/or skin.

of these cases were triple negative [HER2 gene (-), ER (-) and PR (-)], 2 were HER2 gene positive with the HER2 protein mismatching by IHC and 2 were HER2 gene positive with a HER2 protein overexpression score of $2^{+}$and $3^{+}$, respectively. The 2 triple negative cases ( 4 and 5) had a poor outcome, and the patients survived for $<30$ months. The 2 cases in which HER2 gene amplification and protein overexpression matched (cases 3 and 6) were treatable with trastuzumab in the early stage of illness and the patients survived for $>48$ months. However, the 2 cases showing a mismatch between positive HER2 gene amplification and negative protein overexpression (cases 1 and 2) were not treatable with trastuzumab, and the patients showed a very short survival of $<22$ months.

\section{Discussion}

Determining the HER2 status in breast cancer is extremely important, not only in metastatic disease to determine eligibility for trastuzumab therapy but also in an adjuvant setting for the selection of appropriate chemotherapy (11-13). For the clinical determination of the HER 2 status, the US Food 

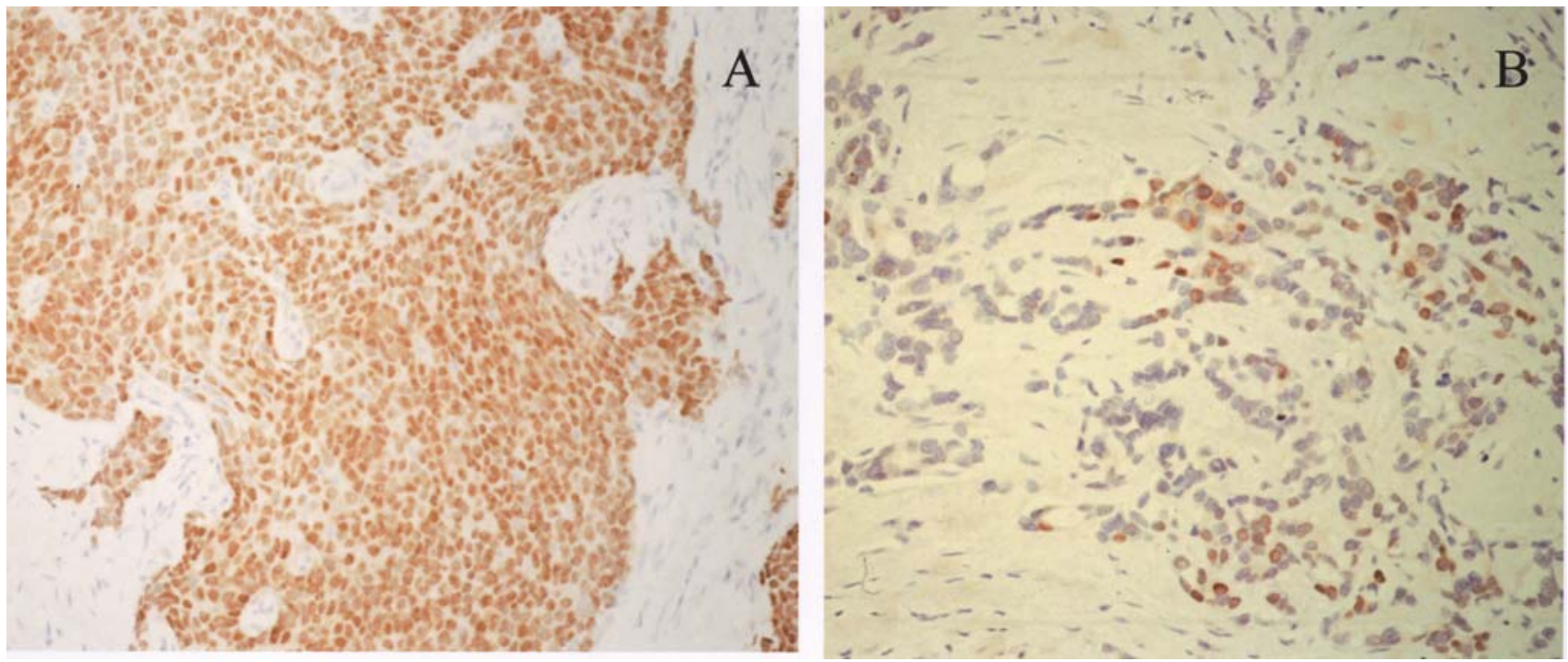

Figure 3. Estrogen receptor (ER) (A) and progesterone receptor (PR) (B) expression determined by IHC in breast cancers (ER and PR, $2=<2.0$ is positive).

Table II. Relationship of HER2 gene amplification and protein overexpression in 6 deceased cases.

\begin{tabular}{lccccccccr}
\hline & $\begin{array}{c}\text { Age } \\
\text { (years) }\end{array}$ & $\begin{array}{c}\text { TNM } \\
\text { stage }\end{array}$ & ER & PR & HER2 (IHC) & HER2 FISH & $\begin{array}{c}\text { Distant } \\
\text { Metastasis }\end{array}$ & $\begin{array}{c}\text { Relapse } \\
(\mathrm{m})\end{array}$ & Adjuvant Therapy1 $^{\mathrm{b}}$ \\
\hline 1 & 63 & IV & - & - & $1^{+}$ & + & bone, liver & 22 & AC, TXL \\
2 & 56 & IIIc & - & - & 0 & + & bone & 14 & FEC, TXL \\
3 & 43 & IIb & + & + & $3^{+}$ & + & - & 48 & AC, HER + TXT, TXL \\
$4^{\text {a }}$ & 41 & IIIa & - & - & 0 & - & liver & 20 & AC \\
$5^{\text {a }}$ & 64 & IIIb & - & - & $2^{+}$ & - & lung, brain & 30 & AC \\
6 & 58 & IIb & - & + & $2^{+}$ & + & lung & 54 & FEC, HER + TXL \\
\hline
\end{tabular}

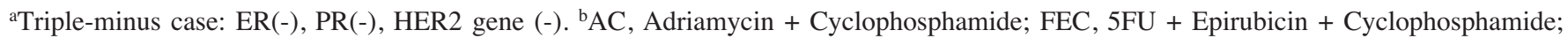
TXL, paclitaxel; TXT, docetaxel and TNM stage, preoperative stage.

and Drug Administration has approved the Hercep Test (Dako, Carpinteria, CA) and Ventana Pathway (Ventana, Tucson, AZ) as IHC assays for the detection of the HER2 protein expression and PathVysion (Vysis) as a FISH method for detecting HER2 gene amplification in breast cancers. Early studies have reported a high level of concordance between the two methods. Lal et al, at the Memorial Sloan Kettering Cancer Center, NY, found a very high concordance rate between IHC scores of $0,1^{+}$and $3^{+}$and FISH data in 2279 cases, whereas only $25 \%$ of cases scored as $2^{+}$by IHC demonstrated gene amplification by FISH (14). In the present study, there was a significant correlation between HER2 gene amplification and HER2 protein overexpression in breast cancers $(\mathrm{P}<0.0001)$. Only $2(20 \%)$ of the cases showing a HER 2 protein score of $2^{+}$by IHC demonstrated HER 2 gene amplification by FISH. However, there was mismatching in 3 cases between HER 2 gene negativity and positivity for HER 2 protein with a score of $3^{+}$, and in 2 cases between HER 2 gene amplification and positivity for HER 2 protein with scores of 0 and $1^{+}$(negative), respectively. These results suggest that detection of the HER2 protein expression by IHC alone is not satisfactory for the evaluation of HER2 status.

Although previous studies have demonstrated a significant correlation between HER2 gene amplification and the expression of hormone receptors (11-13), in the present studies, we found a significant correlation between HER2 gene amplification and the expression of ER $(\mathrm{P}=0.0148)$. We are unable to explain this result, and consider that additional cases will be required to clarify this issue.

HER2 gene amplification and protein overexpression are associated with aggressive biological characteristics and poor clinical outcome in breast cancer patients. However, a consensus has not been reached regarding the value of HER2 as a valid prognostic indicator (15-18). In the present study, we investigated the relationship of HER2 gene amplification and protein overexpression with clinicopathological parameters in 6 deceased cases of breast cancer. We were able to classify these cases into three types: i) triple negativity for HER2, ER and PR, ii) positivity for the HER2 gene amplification with a mismatching of HER2 protein expression demonstrated by 
IHC, and iii) positivity for HER2 gene amplification with matched expression of HER 2 protein with a score of $2^{+}$and $3^{+}$. The triple negative cases had a poor outcome, the cases showing matching between HER2 gene amplification and protein overexpression were treatable with trastuzumab in the early stage of illness and had a positive outcome, and the cases showing the mismatching between positive HER2 gene amplification and negative protein overexpression were not treatable with trastuzumab and had a poor outcome. In clinical practice, we tested for HER2 protein first and then examined HER2 gene amplification by FISH in cases where the HER2 protein expression score was $2^{+}$. Occasionally, therefore, if HER2 protein overexpression is absent and gene amplification is detected later, it may be too late to start trastuzumab therapy. These results suggest that triple negative cases and cases positive for HER2 gene amplification and negative for HER2 protein overexpression have a very poor prognosis. On the other hand, trastuzumab appears to be very effective against breast cancers that are positive for HER2 gene amplification.

On the basis of the present findings, we believe that trastuzumab therapy should be started as soon as possible for cases that are positive for HER2 gene amplification. Merola et al have raised the clinically relevant question of whether patients with polysomy, IHC $2^{+}$and FISH negativity may also benefit from trastuzumab therapy (19) and we think that further studies are required to determine clearly the types of patients who would gain most benefit from trastuzumab.

In conclusion, we believe that detection of the HER2 gene amplification by FISH compared with the HER2 protein expression by IHC is valuable in patients with breast cancer. It also appears that triple negativity for HER2, ER and PR has considerable importance as a potential prognostic indicator.

\section{Acknowledgements}

We thank Ms. Sachiko Nishimura for her expert technical assistance.

\section{References}

1. Schechter AL, Hung MC, Vaidyanathan L, Weinberg RA, Yang-Feng TL, Francke U, Ullrich A and Coussens L: The neu gene: an erbB-homologous gene distinct from and unlinked to the gene encoding the EGF receptor. Science 229: 976-978, 1985.

2. Hynes NE and Stern DF: The biology of erbB-2/neu/HER-2 and its role in cancer. Biochim Biophys Acta 1198: 165-184, 1994.

3. Akiyama T, Sudo C, Ogawara H, Toyoshima K and Yamamoto T: The product of the human c-erbB-2 gene: a 185-kilodalton glycoprotein with tyrosine kinase activity. Science 232: 1644-1646, 1986.

4. Ross JS and Fletcher JA: HER-2/neu (c-erb-B2) gene and protein in breast cancer. Am J Clin Pathol 112: S53-S67, 1999.
5. Shak S: Overview of the trastuzumab (Herceptin) anti-HER2 monoclonal antibody clinical program in HER2-overexpressing metastatic breast cancer. Herceptin multinational investigator study group. Semin Oncol 4: S71-S77, 1999.

6. Ellis IO, Dowsett M, Bartlett J, Walker R, Cooke T, Gullick W, Gusterson B, Mallon E and Lee PB: Recommendations for HER2 testing in the UK. J Clin Pathol 53: 890-892, 2000.

7. Bilous M, Dowsett M, Hanna W, Isola J, Lebeau A, Moreno A, Penault-Llorca F, Rüschoff J, Tomasic G and van de Vijver M: Current perspectives on HER2 testing: A review of national testing guidelines. Mod Pathol 16: 173-182, 2003.

8. Ellis IO, Bartlett J, Dowsett M, Humphreys S, Jasani B, Miller K, Pinder SE, Rhodes A and Walker R: Best practice No. 176: Updated recommendations for HER2 testing in the UK. J Clin Pathol 57: 233-237, 2004

9. Harvey JM, Clark GM, Osborne CK and Allred DC: Estrogen receptor status by immunohistochemistry is superior to the ligand-binding assay for predicting response to adjuvant endocrine therapy in breast cancer. J Clin Oncol 17: 1474-1481, 1999.

10. Allred DC, Harvey JM, Berardo M and Clark GM: Prognostic and predictive factors in breast cancer by immunohistochemical analysis. Mod Pathol 11: 155-168, 1998

11. Burstein HJ, Kuter I, Campos SM, Gelman RS, Tribou L, Parker LM, Manola J, Younger J, Matulonis U, Bunnell CA, Partridge AH, Richardson PG, Clarke K, Shulman LN and Winer EP: Clinical activity of trastuzumab and vinorelbine in women with HER2-overexpressing metastatic breast cancer. J Clin Oncol 19: 2722-2730, 2001.

12. Montemurro F, Choa G, Faggiuolo R, Donadio M, Minischetti M, Durando A, Capaldi A, Vietti-Ramus G, Alabiso O and Aglietta M: A phase II study of three-weekly docetaxel and weekly trastuzumab in HER2-overexpressing advanced breast cancer. Oncology 66: 38-45, 2004.

13. Montemurro F, Valabrega G and Aglietta M: Trastuzumabbased combination therapy for breast cancer. Expert Opin Pharmacother 5: 81-96, 2004.

14. Lal P, Salazar PA, Hudis CA, Ladanyi M and Chen B: HER-2 testing in breast cancer using immunohistochemical analysis and fluorescence in situ hybridization: a single-institution experience of 2,279 cases and comparison of dual-color and single-color scoring. Am J Clin Pathol 121: 631-636, 2004.

15. Slamon DJ, Clark GM, Wong SG, Levin WJ, Ullrich A and McGuire WL: Human breast cancer: correlation of relapse and survival with amplification of the HER-2/neu oncogene. Science 235: 177-182, 1987

16. Paik S, Hazan R, Fisher ER, Sass RE, Fisher B, Redmond C, Schlessinger J, Lippman ME and King CR: Pathologic findings from the National Surgical Adjuvant Breast and Bowel Project: prognostic significance of erbB-2 protein overexpression in primary breast cancer. J Clin Oncol 8: 103-112, 1990.

17. Toikkanen S, Helin H, Isola J and Joensuu H: Prognostic significance of HER-2 oncoprotein expression in breast cancer: a 30-year follow-up. J Clin Oncol 10: 1044-1048, 1992.

18. Park K, Han S, Kim HJ, Kim J and Shin E: HER2 status in pure ductal carcinoma in situ and in the intraductal and invasive components of invasive ductal carcinoma determined by fluorescence in situ hybridization and immunohistochemistry. Histopathology 48: 702-707, 2006.

19. Merola R, Mottolese M, Orlandi G, Vico E, Cognetti F, Sperduti I, Fabi A, Vitelli G and Cianciulli AM: Analysis of aneusomy level and HER-2 gene copy number and their effect on amplification rate in breast cancer specimens read as $2+$ in immunohistochemical analysis. Eur J Cancer 42: 1501-1506, 2006. 